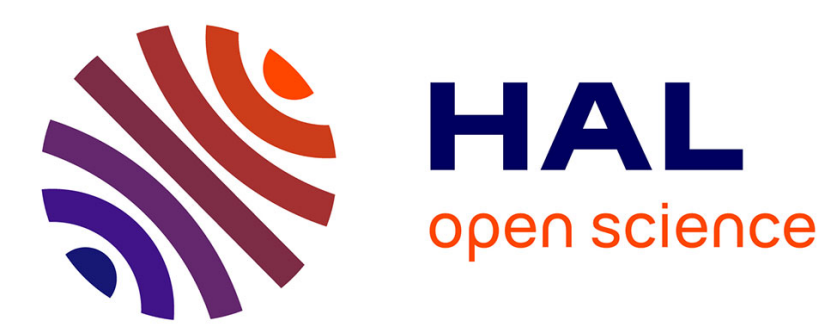

\title{
Methods for the very early selection of Pinus radiata D. Don. for solid wood products
}

\author{
Shakti Chauhan, Monika Sharma, Jimmy Thomas, Luis Apiolaza, David \\ Collings, John Walker
}

\section{- To cite this version:}

Shakti Chauhan, Monika Sharma, Jimmy Thomas, Luis Apiolaza, David Collings, et al.. Methods for the very early selection of Pinus radiata D. Don. for solid wood products. Annals of Forest Science, 2013, 70 (4), pp.439-449. 10.1007/s13595-013-0270-3 . hal-01201483

\section{HAL Id: hal-01201483 \\ https://hal.science/hal-01201483}

Submitted on 17 Sep 2015

HAL is a multi-disciplinary open access archive for the deposit and dissemination of scientific research documents, whether they are published or not. The documents may come from teaching and research institutions in France or abroad, or from public or private research centers.
L'archive ouverte pluridisciplinaire HAL, est destinée au dépôt et à la diffusion de documents scientifiques de niveau recherche, publiés ou non, émanant des établissements d'enseignement et de recherche français ou étrangers, des laboratoires publics ou privés. 


\title{
Methods for the very early selection of Pinus radiata D. Don. for solid wood products
}

\author{
Shakti S. Chauhan - Monika Sharma • Jimmy Thomas • \\ Luis A. Apiolaza • David A. Collings • John C. F. Walker
}

Received: 20 August 2012 / Accepted: 5 February 2013 / Published online: 9 April 2013

(C) INRA and Springer-Verlag France 2013

\begin{abstract}
- Introduction There has been an increasing interest in very early selection of radiata pine to reduce the breeding cycle for solid wood products. For such selection, new approaches are required to assess wood quality in wood from very young stems. - Methods Nursery seedlings of clones of radiata pine were grown in leant condition using two leaning strategies for 18-20 months. Opposite wood and compression wood were
\end{abstract}

Handling Editor: Barry Alan Gardiner

Contribution of co-authors All co-authors have contributed equally in preparation of this manuscript.

Specific contributions Monika Sharma was involved in measuring wood properties. Jimmy Thomas and Dr. David Collings have developed protocols for image analysis and estimating compression wood area in the disc. Dr. Luis Apiolaza and Prof. John Walker conceived the idea of very early selection of radiata pine for solid wood, tilting trees and laying the experimental trial. They are the project leaders of 'Compromised wood quality' under which this study was taken up. The study was carried out when the corresponding author was at School of Forestry, University of Canterbury, Christchurch, New Zealand.

S. S. Chauhan $(\bowtie)$

Institute of Wood Science and Technology,

Malleswaram, Bangalore 560003, India

e-mail: shakti@icfre.org

S. S. Chauhan

e-mail: shakti32@gmail.com

M. Sharma $\cdot$ L. A. Apiolaza J. C. F. Walker

School of Forestry, University of Canterbury, Private Bag 4800,

Christchurch 8140, New Zealand

J. Thomas $\cdot$ D. A. Collings

School of Biological Science, University of Canterbury,

Private Bag 4800, Christchurch 8140, New Zealand

J. Thomas

Central Wood Testing Laboratory, The Rubber Board,

Kottayam, Kerala 686018, India isolated from the leaning stems and tested for dynamic modulus of elasticity, density, longitudinal shrinkage, volumetric shrinkage and compression wood area using new methods evolved for testing small size samples quickly and reliably. The methods were tested for their efficiency in differentiating clones by their wood properties.

- Results Leaning of stems provided distinct opposite and compression wood for testing. Automated image analysis method used for compression wood area assessment was found to be a quick and effective method for processing large number of samples from young stems. Compression wood was characterised by high basic density, high longitudinal shrinkage and low volumetric shrinkage than that of opposite wood. Acoustic velocity in opposite wood had a strong negative association with longitudinal shrinkage. The study signifies the importance of preventing mixing of opposite wood with compression wood while assessing wood quality in young stems thus making leaning a critical strategy. The comparison of wood properties of opposite wood revealed significant differences between clones. Opposite wood of the clone with the lowest dynamic modulus of elasticity exhibited the highest longitudinal shrinkage.

- Conclusion Significant differences in measurable wood properties between clones suggest the prospects of early selection for solid wood products.

Keywords Early selection $\cdot$ Leaning $\cdot$ Radiata pine $\cdot$ Tree clones $\cdot$ Wood properties

\section{Introduction}

Wood quality has increasingly become an integral part of breeding objectives for radiata pine (Pinus radiata $\mathrm{D}$. Don). Historically, wood density was considered to be the most important wood quality trait, principally because this was easily measured and because this trait is closely linked with 
the wood fibre yield, an important criterion for pulp. However, breeding objectives for solid wood products require measurement of a diverse range of traits relating to stiffness, strength, stability and appearance. In recent years, wood stiffness has received consideration in selection of breeding materials because it is practical to estimate dynamic modulus of elasticity (DMoE) of stem bolt section or standing stem through the use of acoustics (Lindström et al. 2002, 2004).

Currently, selection of elite breeding material for solid wood focuses on growth and form, and occurs around 815 years of age for a rotation period of 25-30 years for radiata pine in Australia and New Zealand. Any reduction in the breeding cycle would provide significant economic benefits for production forestry. While most studies on early selection have concentrated on the efficiency of early selection based on age-age correlations of few traits (Wu et al. 2007; Li and Wu 2005), Apiolaza (2009) has advocated very early selection to identify the best and worst segments in breeding populations with reasonable accuracy so as to reduce the generation interval. However, such early selection for wood quality needs rapid and reliable methods of wood quality assessment of a large breeding population.

The use of conventional assessment methods for traits like basic density, modulus of elasticity (MoE), longitudinal shrinkage and volumetric shrinkage would be enormously demanding if one were to evaluate a large number of trees $(>1,000)$ when the trees were $1 / 3$ to $1 / 2$ of the rotation age. These conventional assessment tools would be of limited use when dealing with very young trees (age 1-2) as the physical dimensions of any sample would be limiting. Further, testing of very young samples would be compromised by the presence of a large proportion of reaction wood as young stems are seldom perfectly straight without any compression wood (Nakada 2007) so one is neither analysing pure normal wood nor pure compression wood. The mixing of compression wood with normal wood will lead to significant errors/noise when screening breeding populations for wood quality, particularly in young stems. The properties of compression wood are significantly different from the normal wood and opposite wood. Opposite wood is non-compression wood in the same ring but on the opposite side of the stem to a zone of compression wood. Normal wood is defined as wood from a growth ring that does not contain any compression wood (Donaldson et al. 2004). Compression wood is generally characterised by relatively large microfibril angle (MFA $>30^{\circ}$ ), low MoE, high basic density and high longitudinal shrinkage as compared to normal wood (Timell 1986; Huang et al. 2003).

In this paper, we present new approaches for very early selection of radiata pine at the age of 18-20 months. The paper describes tools and methodologies for evaluating stiffness and stability traits relevant for structural timber production. The developed procedures were tested in young stems from four clones to assess their efficiency in capturing wood property differences at a very early age.

\section{Material and methods}

Nursery seedlings (9 months old) of four clones of radiata pine were planted in 1001 planter bags in August 2007. Soil quality and watering conditions were kept uniform in all the planter bags to eliminate any influence of soil and moisture variability on wood quality. The clones (coded as A, F, K, and $\mathrm{W}$ ) were obtained from ArborGen, New Zealand and covered a range of the standardized predicted genetic values for stiffness, from the top decile (clone $\mathrm{K}$ ) to the bottom decile (clone F).

The tendency for leaning gymnosperms to form compression wood on the lower side of the stem and opposite wood on the upper side of the stem was utilized to overcome uncertainty of the random distribution and intensity of compression wood. Young stems were artificially leant at an angle of about $25-30^{\circ}$ from the vertical axis to produce compression wood and opposite wood for characterization.

Two different leaning strategies were tried. Clones A and $\mathrm{K}(n=22$ and 16 , respectively) were grown straight without any leaning for nearly six months (until April 2008) and then they were grown on tilted platforms, creating leant condition, for one year (April 2008-March 2009; Fig. 1a). Clones $\mathrm{W}$ and $\mathrm{F}$ ( $n=9$ each) were mechanically tilted to produce lean two months after the plants established themselves in the planter bags (Fig. 1b) and grown for two years (October 2007-September 2009). The imbalance in plant numbers is due to limited availability of plants for the study as these clones were also used for another experiment. Clones A and K were processed in April 2009 and clones $\mathrm{W}$ and $\mathrm{F}$ were processed in September 2009. In both leaning

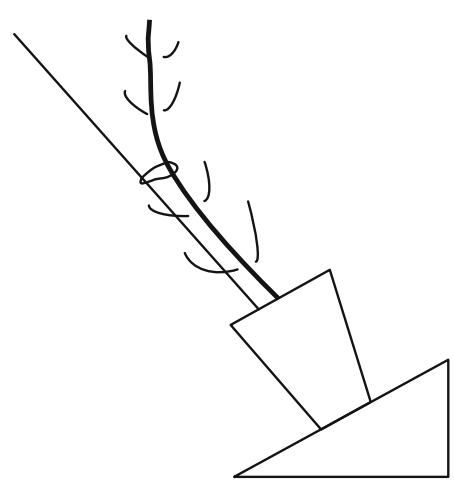

(a)

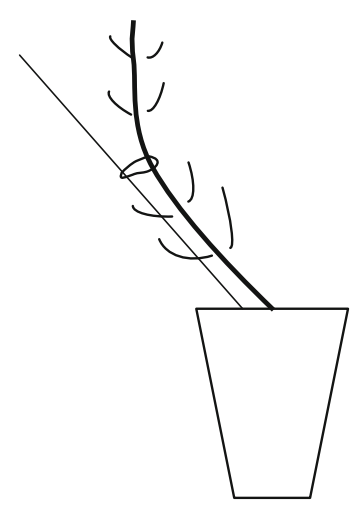

(b)
Fig. 1 Plant tilting schemes a on a sloping platform forming a natural lean and $\mathbf{b}$ mechanically leant with the support of a stake 
procedures, stems were leant with the support of stakes up to $40-50 \mathrm{~cm}$ from the base to get a straight clear bolt section for wood quality analysis with compression wood on the lower side of the stem and opposite wood on the upper side. The upper portion of the stem was kept free to reorient and grow vertically.

All stems were measured for height, root collar diameters in the direction of lean and perpendicular to the lean before processing. On an average stems had achieved about $2 \mathrm{~m}$ height and $4 \mathrm{~cm}$ root collar diameter at the time of felling. A clearwood bolt segment of about $150 \mathrm{~mm}$ length was extracted from the bottom portion of each stem. In addition to the small bolt, 25 -mm-thick disks were extracted from the stems at three different heights. The first disk was taken from the base of the tree and the other two disks were extracted from the vertically growing reoriented stems to observe the proportion of compression wood in vertical segments. The percentage compression wood area was determined for each of the disk (see details below).

The extracted bolt segments (3.5-4 cm diameter) were sawn along the length using a purpose built micro-circular saw to get compression and opposite wood segments with nearly semi-circular cross sections from each of the stems. Due to the stem eccentricity, compression wood segments were about 1.5 to $2 \mathrm{~cm}$ thick whereas opposite wood segments were about 1 to $1.5 \mathrm{~cm}$ thick. The segments were further trimmed to $100 \mathrm{~mm}$ in length to get samples for wood properties assessment. The samples were weighed to an accuracy of $0.001 \mathrm{~g}$ and measured for volume by weighing under water (Kollman and Côté 1968) to an accuracy of $0.01 \mathrm{~cm}^{3}$. Thereafter, all the samples were measured for acoustic velocity and length (see details below).

Subsequently, samples were dried in an oven at $35{ }^{\circ} \mathrm{C}$ until they achieved a constant weight. The purpose of drying samples at $35^{\circ} \mathrm{C}$ was to avoid any thermal degradation of chemical constituents of wood that would compromise further chemical characterization. Drying at $35{ }^{\circ} \mathrm{C}$ did not remove moisture completely from wood; thus, in this paper, all wood property measured in the 'dry condition' actually correspond to measurements at $4.5 \%$ moisture content $(\mathrm{mc})$. Longitudinal dimensions, acoustic velocity, weight and volume were re-measured in the oven dried samples. The volume in the dried condition was measured the same way as in the green condition. To avoid the formation of air bubbles on wood surfaces on immersion in water that can result in errors in volume measurement, dried samples were wiped all over using a damp cloth prior to immersion. To avoid any error due to possible water absorption, the measurement was done very quickly (in less than $5 \mathrm{~s}$ ).

Basic density was determined as the sample weight at $4.5 \% \mathrm{mc}$ divided by the volume of the sample measured in green condition. Volumetric shrinkage (green to $4.5 \% \mathrm{mc}$ ) was determined from the volumes measured in green and oven dried conditions using the following formula:

Volumetric shrinkage $(\%)=\frac{\text { Volume }_{\text {green }}-\text { Volume }_{\text {dried }}}{\text { Volume }_{\text {green }}} \times 100$

\subsection{Compression wood area assessment}

Wood disks (25 mm thick) were debarked and fixed in formalin-acetic acid-alcohol fixative (FAA; 10 parts $37 \%$ formaldehyde, 5 parts glacial acetic acid, 50 parts ethanol and 35 parts distilled water). Wet cross sections were scanned with a flatbed scanner (Epson Perfection V700 Photo) at identical scanning conditions (48 bit colour, $1,200 \mathrm{dpi}$ ) and saved as TIFF images. The area of compression wood was measured by batch processing the images in Adobe Photoshop CS4 (version 11.0.1, Adobe Systems, San Jose, CA USA) using a series of predefined image processing steps termed 'actions'. Image thresholding was used to define the cross section relative to the background and to measure its area. Compression wood was identified using separate image thresholding so that the non-compression wood (opposite wood and normal wood) and compression wood were distinguishable. Compression wood regions were processed by serial image expansion (image dilation) and contraction (image erosion) and the areas of compression wood then automatically measured. Automatic detection of compression wood on disk cross section was visually verified by the colour difference between non-compression and compression wood. Data were exported to Microsoft Excel for analysis. This process has the advantages of being significantly faster to process large number of cross sectional images and being more objective than manual analysis. This automatic compression wood detection method using the batch processing tool in Photoshop was verified manually by using other Photoshop tools such as magic wand and selection tools. Figure 2 shows an example of automatic detection and quantification of compression wood based on its colour intensity by image analysis in two disks.

\subsection{Acoustic velocity measurement}

Measurements of acoustic velocity $(V)$ and wood density $(\rho)$ at the time of velocity measurement provide a quick determination of the dynamic modulus of elasticity (DMoE) by the formula:

$D M o E=\rho V^{2}$

The dynamic modulus of elasticity as determined by acoustic velocity has been reported to have moderate to strong correlation (correlation coefficient ranging from 0.61 to 0.98 ) with the static MoE (Ross and Pellerin 1991; 
Fig. 2 Images of the compression wood area in the stem cross section of two radiata pine plants from the study. Extreme left is the scanned image of the disks, the centre image is manually (user) defined area of compression wood and extreme right is the automatically defined area of compression wood in the disks

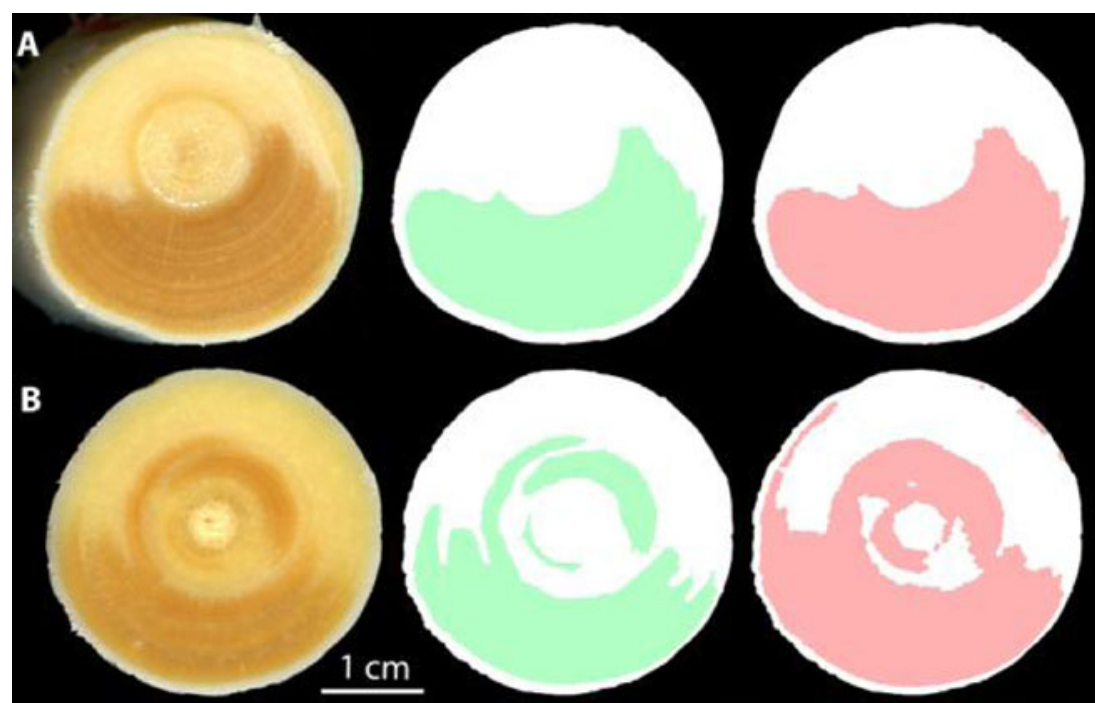

Disc image

Automatic detection
Halabe et al. 1997; Wang et al. 2000; Lindstrom et al. 2002). Acoustic velocity can either be measured in standing stems using a time of flight method or by localising the resonance frequencies of longitudinal vibrations in cut samples. Among the two methods, the resonance method is considered to be a reliable and accurate method for obtaining the area weighted average velocity of the entire sample as the velocity is determined from the frequency of many tens of reverberations of the acoustic signal within the sample (Andrews 2002). However, the method is destructive and can be used only on cut samples. Acoustic velocity is calculated from the fundamental frequency of longitudinal vibration $(f)$ and sample length $(l)$ using the following equation

\section{$V=2 f l$}

In this study, acoustic velocity in all the samples was measured using a resonance tool 'Woodspec'. The tool was the first generation resonance tool designed and developed by Industrial Research Laboratory (Wellington New Zealand) to measure acoustic velocity from the resonance frequency of longitudinal vibration in small bolts and samples. Resonance frequencies can be obtained by either sweeping a range of frequencies through the wood along the sample length or by tapping gently at a cut face without exciting other vibration mode e.g. flexural or torsional. The tool was used in the frequency sweep mode where a small piezo-speaker was used to sweep across a range of frequencies from 500 to $20,000 \mathrm{~Hz}$. The piezo-speaker was gently kept in contact to one cut face of the sample and frequencies were swept through the sample for one second. A microphone was placed very close to the other face of the sample to capture the vibrations in the sample. A Fast Fourier Transformation (FFT) of the captured signal was performed by the inbuilt software to identify the resonance frequencies of the sample and calculate acoustic velocity. Swept frequency testing ensured the piezo-speaker generated known magnitude signals throughout the swept band, considerably aiding harmonic analysis and repeatability.

The acoustic velocity was determined in both green and oven dried conditions for each sample. Dynamic $\mathrm{MoE}$ in green condition was determined from the acoustic velocity measured in the green condition and the green density.

\subsection{Longitudinal shrinkage measurement}

A special device attached with a micrometer was designed (Fig. 3) to measure longitudinal shrinkage in short samples. In this procedure, two map pins were inserted in line on the opposite end faces of each specimen. The pin heads become the reference points for the length measurement. The sample was placed on the device and a micrometer reading was recorded. The measurements were observed to be highly repeatable ensuring the consistency and accuracy of longitudinal dimensions measurements which are paramount to longitudinal shrinkage measurements. Longitudinal dimensions were recorded both in green and dry conditions to

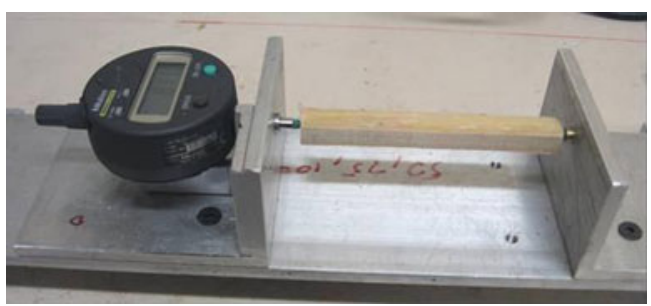

Fig. 3 The fabricated device for measuring longitudinal dimensions in short samples 
estimate longitudinal shrinkage (LS) using the following formula:

$\operatorname{LS}(\%)=\frac{L_{\text {green }}-L_{d r y}}{L_{\text {green }}} \times 100$

Where $L_{\text {green }}$ and $L_{\text {dry }}$ are the longitudinal dimension measured in sample in green and oven dried $(4.5 \% \mathrm{mc})$ conditions, respectively

\subsection{Data analysis}

Data were analysed using SAS (Ver. 9.2) statistical software. Tukey's HSD test was used to assess the significant differences in wood quality between opposite wood and compression wood. A Pearson's correlation analysis was performed to find out the relationship in wood properties within opposite wood and compression wood with pooled data.

\section{Results}

\subsection{Compression wood area}

Compression wood area measured in different clones at three different heights is given in Table 1. The bottom disk had maximum compression wood and the top disk had the minimum compression wood area. The average area of compression wood in bottom disks of clone $\mathrm{A}$ and $\mathrm{K}$ was $31.9 \%$ and $33.8 \%$, respectively, whereas in clone $\mathrm{W}$ and $\mathrm{F}$ it was $45.3 \%$ and $42.2 \%$, respectively. Compression wood area measured by the automatic detection procedure was in good agreement with the manual identification method (Fig. 4).

\subsection{Wood property variation between clones}

\subsubsection{Opposite wood}

The measured wood properties for opposite wood are given in Table 2. Opposite wood samples had a high initial moisture content with individual values ranging from $159 \%$ to $226 \%$ while average values for clones ranged from $176 \%$

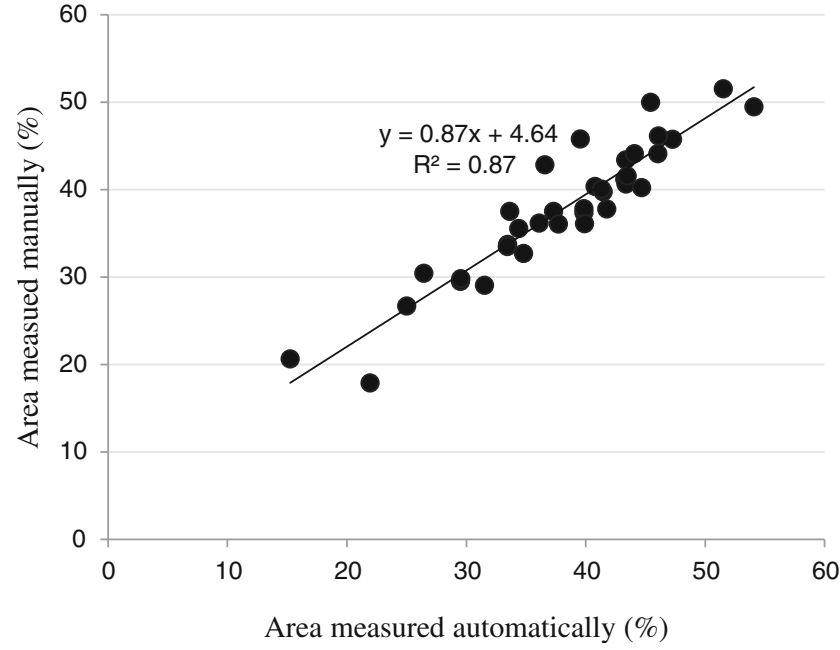

Fig. 4 Relationship between manually and automatically detected compression wood area in the disks. Manual detected values corresponded well with automatic detection

(clone K) to $206 \%$ (clone $\mathrm{W}$ ). Among the four clones, green and dry acoustic velocities of opposite wood were the lowest for clone $\mathrm{F}(1.26 \mathrm{~km} / \mathrm{s}$ in green condition and $2.75 \mathrm{~km} / \mathrm{s}$ in dry condition) and were significantly different from other clones (A, K and W). Similarly to green velocity, the green $\mathrm{DMoE}$ of clone $\mathrm{K}$ was the highest $(2.31 \mathrm{GPa})$ followed by clone A $(2.21 \mathrm{GPa}), \mathrm{W}$ $(2.08 \mathrm{GPa})$ and $\mathrm{F}(1.69 \mathrm{GPa})$. The stiffness of clone $\mathrm{K}$ was nearly $36 \%$ higher than the poorest clone while the basic density of clone $\mathrm{K}\left(395 \mathrm{kgm}^{-3}\right)$ was also significantly higher than the density of other clones. No significant difference was observed in basic densities of clones $\mathrm{A}, \mathrm{W}$ and $\mathrm{F}$. Thus, clone $\mathrm{K}$ appeared to be the best clone in terms of stiffness and density. Ranking of the clones for longitudinal shrinkage (green to $4.5 \% \mathrm{MC}$ ) was different with clone $\mathrm{W}$ exhibiting the minimum shrinkage $(0.48 \%)$ followed by clones K (0.67\%), A (0.69\%) and $\mathrm{F}(0.73 \%)$. Longitudinal shrinkage in clones $\mathrm{A}$ and $\mathrm{K}$ exhibited relatively large variability within the clone (a very high coefficient of variation) as compared to variability in clones $\mathrm{W}$ and $\mathrm{F}$. Opposite wood volumetric shrinkage in clone $\mathrm{A}$ was significantly lower $(12.20 \%)$ than for clones $\mathrm{K}, \mathrm{W}$ and $\mathrm{F}$.

Table 1 Average area of compression wood, as a percentage of wood cross sectional area, in disks extracted from different positions

\begin{tabular}{|c|c|c|c|c|c|c|c|c|}
\hline \multirow[t]{2}{*}{ Position } & \multicolumn{2}{|l|}{ Clone A } & \multicolumn{2}{|l|}{ Clone K } & \multicolumn{2}{|l|}{ Clone W } & \multicolumn{2}{|l|}{ Clone F } \\
\hline & auto & man & auto & man & auto & man & auto & $\operatorname{man}$ \\
\hline Top & $13.2(6.8)$ & $16(7.1)$ & $20.7(8.4)$ & $25.7(9.1)$ & $21.7(14.9)$ & $22.9(9.6)$ & $20.1(6.7)$ & $24.2(7.7)$ \\
\hline Middle & $23.2(7.6)$ & $25.4(5.7)$ & $22.5(5.8)$ & $26.3(7.4)$ & $36.1(4.3)$ & $33.4(4.2)$ & 31.9 (11.6) & $30.0(10.6)$ \\
\hline Bottom & $31.9(5.8)$ & $32.5(7.1)$ & $33.8(9.5)$ & $35.7(7.8)$ & $45.3(2.9)$ & $45.3(4.1)$ & $42.2(5.4)$ & $39.1(4.7)$ \\
\hline
\end{tabular}

Values in parentheses are standard deviation. Note: auto-automatic image analysis method; man-Manual method 
Table 2 Mean and coefficient of variation (in parentheses) for measured variables for opposite wood

\begin{tabular}{|c|c|c|c|c|}
\hline Variables & A & $\mathrm{K}$ & W & $\mathrm{F}$ \\
\hline Green moisture content (\%) & $192(7.97)^{\mathrm{a}}$ & $176(7.36)^{b}$ & $206(5.76)^{\mathrm{a}}$ & $192(8.60)^{\mathrm{a}}$ \\
\hline Green density $\left(\mathrm{kgm}^{-3}\right)$ & $1066(2.08)^{\mathrm{a}}$ & $1088(1.55)^{\mathrm{a}}$ & $1065(1.65)^{\mathrm{a}}$ & $1065(1.37)^{\mathrm{a}}$ \\
\hline Green velocity $\left(\mathrm{kms}^{-1}\right)$ & $1.44(7.51)^{\mathrm{a}}$ & $1.45(9.92)^{\mathrm{a}}$ & $1.40(6.50)^{\mathrm{a}}$ & $1.26(7.13)^{b}$ \\
\hline Oven dried velocity $\left(\mathrm{kms}^{-1}\right)$ & $2.95(6.39)^{\mathrm{a}}$ & $2.92(7.53)^{\mathrm{a}}$ & $2.94(4.88)^{\mathrm{a}}$ & $2.75(4.62)^{b}$ \\
\hline Basic density $\left(\mathrm{kgm}^{-3}\right)$ & $366(4.55)^{\mathrm{a}}$ & $395(5.04)^{b}$ & $348(4.35)^{\mathrm{a}}$ & $367(6.14)^{\mathrm{a}}$ \\
\hline Green DMoE (GPa) & $2.21(14.07)^{\mathrm{a}}$ & $2.31(19.11)^{\mathrm{a}}$ & $2.08(12.92)^{\mathrm{a}}$ & $1.69(15.19)^{b}$ \\
\hline Longitudinal shrinkage (green to $4.5 \% \mathrm{MC}$ ) & $0.69(33.96)^{\mathrm{a}}$ & $0.67(29.23)^{\mathrm{ab}}$ & $0.48(19.01)^{b}$ & $0.73(12.67)^{\mathrm{a}}$ \\
\hline Volumetric shrinkage (green to $4.5 \% \mathrm{MC}$ ) & $12.20(15.24)^{\mathrm{a}}$ & $14.28(14.15)^{\mathrm{ab}}$ & $15.38(19.39)^{\mathrm{b}}$ & $16.48(8.93)^{b}$ \\
\hline
\end{tabular}

Multiple comparisons between clones use the same letter (superscript) to denote not statistically different means as per Tukey's test (at $\alpha=0.05$ )

$M C$ moisture content

\subsubsection{Compression wood}

The measured properties for compression wood are given in Table 3. There was no significant difference in compression wood moisture content between clones. Similar to opposite wood, acoustic velocity in compression wood of clone $\mathrm{F}$ was the lowest $(1.35 \mathrm{~km} / \mathrm{s}$ in green condition and $2.31 \mathrm{~km} / \mathrm{s}$ in dry conditions). Both velocity and $\mathrm{DMoE}$ of clones $\mathrm{A}$ and $\mathrm{K}$ were significantly higher than of clones $\mathrm{W}$ and $\mathrm{F}$. Basic density of compression wood ranged from 558 to $585 \mathrm{~kg}$ $\mathrm{m}^{-3}$ between the clones but it did not differ significantly. Similarly, clones did not exhibit significant differences in their compression wood longitudinal shrinkage though shrinkage was maximum in clone $\mathrm{F}(3.22 \%)$ and minimum in clone A (2.98\%). Compression wood volumetric shrinkage of clones $\mathrm{A}$ and $\mathrm{K}$ was higher than of clones $\mathrm{W}$ and $\mathrm{F}$.

\subsection{Wood property variation between wood types}

Between the opposite wood and compression wood, all the measured properties in compression wood were significantly different from the opposite wood properties. The initial moisture content of compression wood was nearly half than the moisture in opposite wood. The basic density of compression wood was about 50-58 \% higher than that of opposite wood. Compression wood acoustic velocity was also consistently higher in green condition implying a higher stiffness (DMoE) of compression wood than opposite wood. However, in dry condition, opposite wood acoustic velocities were significantly higher (14-20\%) than the compression wood velocities. Interestingly, compression wood longitudinal shrinkage was three to four times higher than the opposite wood longitudinal shrinkage but the compression wood volumetric shrinkage was much lower than the opposite wood volumetric shrinkage.

The relationships of opposite wood and compression wood properties are shown in Figs. 5, 6 and 7. No significant association was apparent between opposite wood and compression wood basic density (Fig. 5). Longitudinal shrinkage and acoustic velocity in compression wood exhibited a positive trend but with a low coefficient of determination, to these properties in opposite wood (Figs. 6 and 7). Compression wood volumetric shrinkage was also independent of opposite wood volumetric shrinkage.

Table 3 Mean and coefficient of variation (in parentheses) for measured variables for compression wood

\begin{tabular}{|c|c|c|c|c|}
\hline Variables & A & $\mathrm{K}$ & $\mathrm{W}$ & $\mathrm{F}$ \\
\hline Green moisture content $(\%)$ & $95(19.75)^{\mathrm{a}}$ & $100(19)^{\mathrm{a}}$ & $97(10.03)^{\mathrm{a}}$ & $103(11.74)^{\mathrm{a}}$ \\
\hline Green density $\left(\mathrm{kgm}^{-3}\right)$ & $1131(2.80)^{\mathrm{a}}$ & $1141(1.84)^{\mathrm{a}}$ & $1132(1.67)^{\mathrm{a}}$ & $1131(1.91)^{\mathrm{a}}$ \\
\hline Green velocity $\left(\mathrm{kms}^{-1}\right)$ & $1.64(7.06)^{\mathrm{a}}$ & $1.59(6.36)^{\mathrm{a}}$ & $1.45(5.92)^{\mathrm{b}}$ & $1.35(6.41)^{\mathrm{b}}$ \\
\hline Oven dried velocity $\left(\mathrm{kms}^{-1}\right)$ & $2.61(3.39)^{\mathrm{a}}$ & $2.56(4.70)^{\mathrm{a}}$ & $2.40(3.15)^{\mathrm{b}}$ & $2.31(3.56)^{\mathrm{b}}$ \\
\hline Basic density $\left(\mathrm{kgm}^{-3}\right)$ & $585(9.51)^{\mathrm{a}}$ & $579(9.57)^{\mathrm{a}}$ & $576(6.27)^{\mathrm{a}}$ & $558(7.79)^{\mathrm{a}}$ \\
\hline Green DMoE (GPa) & $3.07(14.51)^{\mathrm{a}}$ & $2.92(12.36)^{\mathrm{a}}$ & $2.39(13.43)^{\mathrm{b}}$ & $2.07(14.05)^{\mathrm{b}}$ \\
\hline Longitudinal shrinkage (green to $4.5 \% \mathrm{MC}$ ) & $2.89(19.74)^{\mathrm{a}}$ & $2.98(15.53)^{\mathrm{a}}$ & $2.98(9.86)^{\mathrm{a}}$ & $3.22(12.38)^{\mathrm{a}}$ \\
\hline Volumetric shrinkage (green to $4.5 \% \mathrm{MC}$ ) & $9.63(16.57)^{\mathrm{ab}}$ & $10.93(19.4)^{\mathrm{b}}$ & $7.07(7.12)^{\mathrm{c}}$ & $8.06(4.22)^{\mathrm{ac}}$ \\
\hline
\end{tabular}

Multiple comparisons between clones use the same letter (superscript) to denote not statistically different means as per Tukey's test (at $\alpha=0.05$ ) $M C$ moisture content 


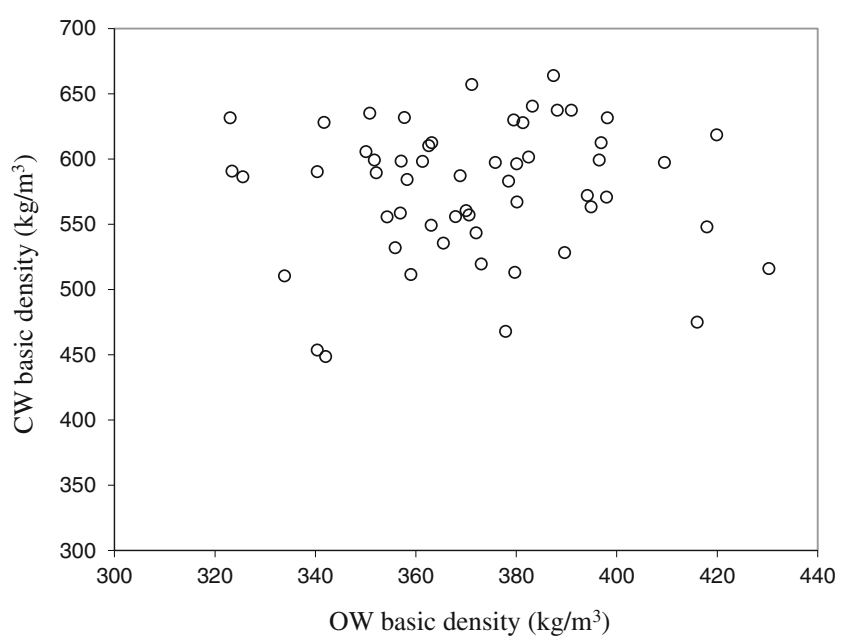

Fig. 5 Relationship between opposite wood (OW) and compression wood $(\mathrm{CW})$ basic density with the pooled data

\subsection{Relationship between wood properties}

The Pearson's correlation matrix revealing the strength of association between different properties is shown in Table 4 . Coefficients in the upper diagonal matrix are for opposite wood and in lower diagonal matrix are for compression wood.

Acoustic velocity and DMoE variables were highly associated with each other in both opposite wood and compression wood. In opposite wood, basic density was not related to any of the measured wood properties. Acoustic velocity (both green and dry) had a highly significant negative association with longitudinal shrinkage. Volumetric shrinkage exhibited a moderate negative association with green acoustic velocity but not with dry velocity.

In compression wood basic density had significant positive relationship with green velocity, $\mathrm{DMoE}$ and longitudinal

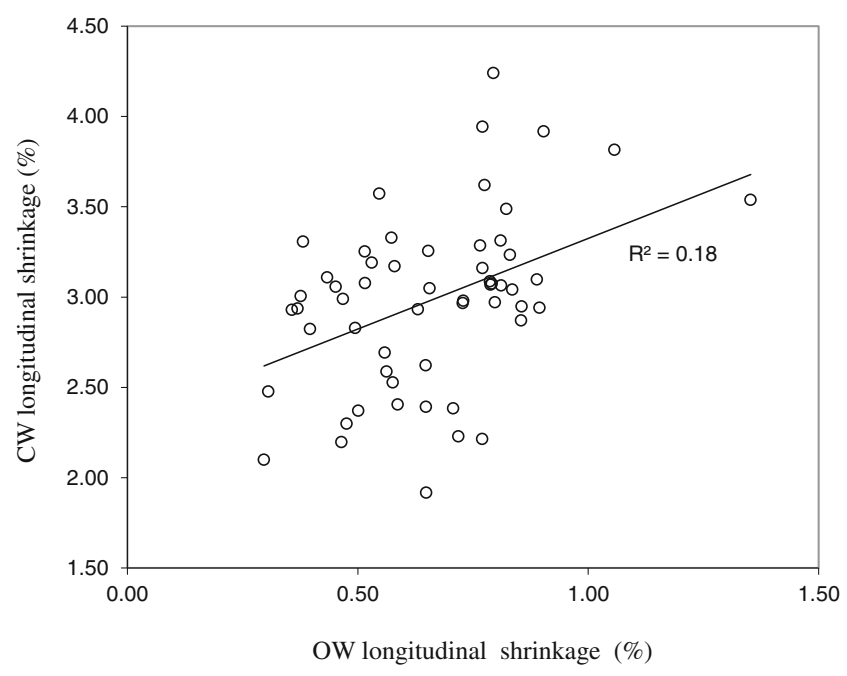

Fig. 6 Relationship between opposite wood (OW) and compression wood $(\mathrm{CW})$ longitudinal shrinkage with the pooled data

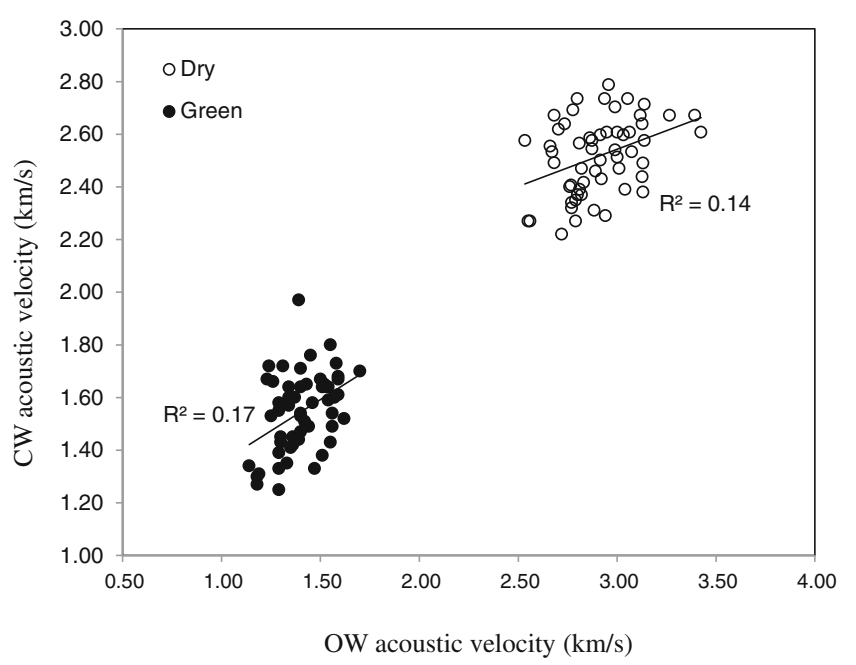

Fig. 7 Relationship between opposite wood (OW) and compression wood $(\mathrm{CW})$ acoustic velocity for dry and green samples with the pooled data

shrinkage but did not exhibit any association with dry velocity and volumetric shrinkage. Though the green acoustic velocity in compression wood did not show a significant association with longitudinal shrinkage, dry velocity exhibited a significant negative association similar to that observed in opposite wood. No significant correlation was observed for volumetric shrinkage with other variables.

\section{Discussion}

\subsection{Methodology}

Artificial leaning of young stems is being used to elucidate the stem reorientation mechanisms in angiosperms (Yoshida et al. 2000) and gymnosperms (Yamashita et al. 2007), and Sierra de Grado et al. (2008) used leaning to study provenance differences aiming at improving stem form in Pinus pinaster. Apiolaza et al. (2011) have indicated leaning as one of the potential ways of screening very young stems for early selection. Leaning at an angle of $25^{\circ}$ from the vertical axis eliminate any uncertainty about the severity and area of compression wood formation as any leaning angle $>25^{\circ}$ does not have any significant effect on the extent of compression wood formation and compression wood characteristics (Yamashita et al. 2007). Lachenbruch et al. (2010) did not observe any significant effect of lean angle above $10^{\circ}$ on the extent of compression wood formation in 2-3 year old radiata pine stems. In our study, trees were leaning at about $25^{\circ}$ in both leaning techniques (on platform and mechanical bending) during their leaning period when the maximum amount of compression wood with uniform properties was expected in the trees. Leaning produced two distinctly different wood types, compression wood on lower side and 
Table 4 Pearson's correlation matrix - upper diagonal coefficients (in bold) are for opposite wood whereas lower diagonal coefficients are for compression wood

\begin{tabular}{lllllll}
\hline Variables & Basic density & Green velocity & OD velocity & Green DMoE & Long. Shrinkage & Vol. shrinkage \\
\hline Basic density & & $\mathbf{0 . 1 7}$ & $-\mathbf{0 . 1 1}$ & $\mathbf{0 . 2 1}$ & $\mathbf{0 . 1 3}$ & $-\mathbf{0 . 1 3}$ \\
Green velocity & $0.46^{* *}$ & & $\mathbf{0 . 8 7 * * *}$ & $\mathbf{0 . 9 9 * * *}$ & $-\mathbf{0 . 5 5} * * *$ & $-\mathbf{0 . 3 9} * *$ \\
Oven dried velocity & -0.03 & $0.83^{* * *}$ & & $\mathbf{0 . 8 6 * * *}$ & $-\mathbf{0 . 5 9 * *}$ & $-\mathbf{0 . 2 9}$ \\
Green DMoE & $0.52^{* * *}$ & $0.99 * * *$ & $0.79^{* * *}$ & & $-\mathbf{0 . 5 3} * * *$ & $-\mathbf{0 . 3 9} * *$ \\
Longitudinal shrinkage & $0.53^{* * *}$ & -0.28 & $-0.57^{* * *}$ & -0.21 & 0.07 & $-\mathbf{0 . 1 1}$ \\
Volumetric shrinkage & 0.06 & 0.22 & -0.27 & 0.24 & \\
\hline
\end{tabular}

$* * P<0.001 ; * * * P<0.0001$

opposite wood on the upper side, to characterise from the same stem.

In the method developed for compression wood area assessment, identical scanning conditions (48 bit colour, 1,200 dpi) enabled uniform image acquisition of each disk which ensured the quality and consistency of the images. These images were obtained in actual dimensions and colour which enabled the accurate detection of compression wood. We used the popular, user-friendly and powerful image processing software, Photoshop CS4. Once the 'actions', which is a set of sequential image processing steps, is prepared, even a less skilled person can process any number of images (samples) in a short time to get accurate results in a few simple and easy steps.

Moreover this automatic image analysis method is advantageous as it applies equal treatment to all images thereby avoiding any possible operator bias in defining the wood cross section and selection of the compression wood area. Separate 'image thresholding' has been applied to differentiate between the wood cross section from the image background and compression wood area from the rest of the wood to ensure consistency and reproducibility in measurements. This method is more objective, quicker and easier to operate than many other methods. A very strong correlation $\left(R^{2}=0.87\right)$ between the methods shows the validity of this new technique (Fig. 4).

In this study, compression wood area in clones $\mathrm{A}$ and $\mathrm{K}$ was substantially smaller (32.6\%) than in clones $\mathrm{W}$ and $\mathrm{F}$ $(43.8 \%)$. These differences in compression wood area were probably due to differences in leaning periods. Clones A and $\mathrm{K}$ were grown straight for nearly one growing season (September 2007 to April 2008) followed by leaning for one year. Thus, all the trees in clone $\mathrm{A}$ and $\mathrm{K}$ formed a large proportion of normal wood during the first six months of active growing period and compression wood was mainly confined to the 2 nd growth ring i.e. in growth during the leaning period. In the case of clone $\mathrm{W}$ and $\mathrm{F}$, the plants were leaning in both active growth periods thus forming compression wood for two growth seasons. In this study, the main objective was to establish the method for area assessment and not the comparison of clones for compression wood development. Quick and reliable methods of compression wood area assessment could be useful in estimating the genetic control of propensity of compression wood formation in large populations of young radiata pine. Lindström et al. (2004) has observed clonal heritability of $27 \%$ and clonal repeatability of $55 \%$ in compression wood area in 3-yr-old radiata pine clones. Differences in the propensity of compression wood formation in genotypes of radiata pine were also reported by Burdon (1975).

One of the most important requirements in large-scale wood quality assessment is to have quick and reliable evaluation tools. Most of the acoustic tools (both transit-time and resonance) are suitable for logs and trees. Ultrasonic pulse timer tools are being used to measure the acoustic velocity in young seedlings but their suitability and accuracy for large scale field measurements is yet to be established (Horvath et al. 2010; Huang and Lambeth 2007). Penetration depths of probes, poor coupling between probe and wood, and presence of any branch node or defects may lead to poor or wrong results. The standing tree measurements also present operational difficulties in the field with significant differences in acoustic velocities observed in opposite and compression wood sides. Therefore the resonance method, though destructive, provides more reliable and repeatable data. Moreover, dynamic MoEs determined from the resonance frequency of longitudinal vibrations have been reported to be in very close agreement with the static MoEs with a correlation coefficient as high as 0.98 (Lindström et al. 2002). The use of piezo-speakers for sweeping the frequencies ensures the excitation of only longitudinal vibrations in the samples as manually tapping can set up flexural and torsional vibration modes in small samples.

Longitudinal shrinkage assessment requires precise measurement of dimensional changes in the longitudinal direction as the shrinkage is very small in this direction. Linear displacement transducers, travelling microscopes or micrometers have been used to measure such small dimensional 
changes (Kretschmann and Cramer 2007; Hai et al. 2009). These methods are time-consuming and enormously demanding, if large number of samples (hundreds and thousands) are to be measured particularly in evaluation of breeding populations. In this study, the method developed for measuring longitudinal dimensions allows highly repeatable and accurate measurements quickly and reliably in large number of samples thus providing an opportunity to include shrinkage associated traits as selection criterion in breeding objectives.

\subsection{Wood properties}

Since compression wood is known to have a relatively large MFA, as compared to normal wood, velocity in compression wood was expected to be lower than opposite wood. However, in green conditions, acoustic velocity in compression wood was higher than the velocity in opposite wood in all the clones. This can be attributed to a difference in initial moisture content which, in the opposite wood samples, was nearly double that in compression wood. When the samples were dried to a uniform moisture level, acoustic velocity in opposite wood was higher than in compression wood as expected.

Despite a large difference in green moisture content, the green density of both opposite and compression wood was very similar due to intrinsic differences in basic densities of cell walls of opposite and compression wood. Therefore, compression wood was stiffer than the opposite wood, which is counter-intuitive. However, it should be noted that the trees were only 18 months old with only juvenile wood in the first two growth rings. The juvenile wood of radiata pine is characterised by high microfibril angle and low density (Donaldson et al. 2004; Huang et al. 2003). Thus, the higher stiffness of compression wood is primarily due to higher density. This is also evident from the relationship between DMoE with acoustic velocity and basic density for both opposite and compression wood. In opposite wood, acoustic velocity is the main determining factor for DMoE, whereas in compression wood, density becomes a dominant factor.

Small differences in acoustic velocity (in the dry condition) between opposite wood and compression wood also suggest that differences in their intrinsic microfibril angle may be very small, as acoustic velocity is considered to be a surrogate measure of MFA (Evans 2000; Huang et al. 2003). Donaldson et al. (2004) observed a very similar and high MFA $\left(\sim 40^{\circ}\right)$ in opposite wood and compression wood in the second growth ring of radiata pine. Similarly a very small difference in MFA in juvenile normal wood $\left(33.6^{\circ}\right)$ and in compression wood $\left(36^{\circ}\right)$ in 2-year old Cryptomeria japonica was reported by Yamashita et al. (2007). Within the wood types, acoustic velocity in dry conditions exhibited a strong negative association with longitudinal shrinkage and this association can be linked with the variation in MFA. However, large differences in longitudinal shrinkage in opposite wood and compression wood with a similar velocity (or MFA) suggest that there might be some other factors contributing to the high longitudinal shrinkage in compression wood. The large axial shrinkage in compression wood has been attributed to the presence of a significant volume of galactan in compression wood (Floyd 2005)

The small volumetric shrinkage of compression wood, as compared to opposite wood, is in agreement with generally observed behaviour of these two wood types (Timell 1986). In mature wood, significant differences in MFA are attributed to the differences in their lateral and axial shrinkage which is not the case in very young juvenile wood and compression wood. A relatively small volumetric shrinkage of compression wood might be due to the absence of the S3 layer in cell walls. The orientation of the microfibrils in the S1 and S3 layers (nearly perpendicular to cell axis) tends to restrain transverse shrinkage/swelling of the cell wall (Booker and Sell 1998). Absence of any restraining force at the inner side of the $\mathrm{CW}$ cell walls leads to pronounced internal shrinkage i.e. increasing the lumen volume. This might result in low net volumetric shrinkage in compression wood. However this needs detailed investigation.

\subsection{Early screening of clones for stiffness and stability}

The results demonstrated that the adopted procedures were capable of segregating the studied genotypes for their wood properties. Among the studied clones, opposite wood of clone $\mathrm{K}$ had the highest $\mathrm{DMoE}$ followed by clones $\mathrm{A}$, W and $\mathrm{F}$. The ranking of the studied clones for genetic values for their stiffness at age 7 is reported as $\mathrm{K}, \mathrm{W}, \mathrm{A}$ and $\mathrm{F}$ (Charles Sorensson, personal communication) which is nearly akin to the ranking observed in this study though the leaning strategies were different for $\mathrm{A}-\mathrm{K}$ and $\mathrm{W}-\mathrm{F}$ clones. Clone $\mathrm{F}$ had the lowest acoustic velocity, DMoE and the highest longitudinal shrinkage. Even the compression wood properties were the poorest for clone $\mathrm{F}$ suggesting that a combination of both opposite wood and compression wood properties can help in screening genotypes more efficiently. However, the variability in measured data particularly in longitudinal shrinkage in clones A and $\mathrm{K}$ was significantly higher than that observed in clones $\mathrm{W}$ and F. The high variability in longitudinal shrinkage within clones $\mathrm{A}$ and $\mathrm{K}$ can be attributed to the random formation of compression wood during the first growing season (September 2007-March 2008) when these trees were growing vertically without any restraint. Young radiata pine stems seldomly grow completely straight and tend to form 
compression wood with continuous reorientation. A large amount of randomly distributed compression wood has been reported. Values include 6-29\% in 3-year-old clonal trial of radiata pine in New Zealand (Lindström et al. 2004) and 6$15 \%$ in 4-year-old radiata pine trees growing in Chile (Lachenburch et al. 2010). On analysing the bottom disks, it was observed that a few disks of clones $\mathrm{A}$ and $\mathrm{K}$ had random distribution of compression wood all over the cross section within the first growth ring (first growing season). Since longitudinal shrinkage in compression wood is three to four fold higher than in opposite wood, a small amount of mixing or contamination of compression wood in the samples extracted from the opposite wood side would result in large longitudinal shrinkage in opposite wood samples. This mixing of compression wood would not be reflected by the acoustic velocity as in juvenile stages, the differences in acoustic velocity in opposite and compression wood are very small (10-15\%). The results emphasise the need of isolating opposite wood and compression wood for the efficient early assessment. Therefore, an early tilting of sapling, as done in case of clone $\mathrm{W}$ and $\mathrm{F}$, is recommended for obtaining opposite wood without any contamination of reaction wood.

\section{Conclusions}

The main purpose of the tools and methodologies discussed in this paper is to develop methods for early segregation of genotypes for their wood quality for solid wood products. The early segregation can either be used to select superior genotypes or to eliminate the worst performers from the breeding populations. The study reveals the possibilities of very early selection of radiata pine clones for superior stiffness and stability. However, this needs to be confirmed in further trials and comparison with the properties of wood from harvested trees. The tools and techniques used for rapid assessment of wood properties in young stems provide enormous opportunities for early selection for solid wood properties and the potential to deploy improved material much faster. Also dealing with very young trees by age 1-2 rather than at age $5-10$ is much simpler, samples are physically smaller, far cheaper to handle and quicker to process and analyse (days and weeks rather than months). This provides the ability to screen large populations.

Acknowledgements Authors are thankful to Nigel Pink and Lachlan Kirk for helping in fabrication of micro-saw, shrinkage jig and processing samples. This work is a part of the Compromised Wood Programme (P2080) funded by Foundation for Research Science and Technology (FRST), New Zealand. Jimmy Thomas gratefully acknowledges funding for his $\mathrm{PhD}$ scholarship generously provided by Scion Ltd, Rotorua, New Zealand.

\section{References}

Andrews M (2002) Which acoustic speed? The 13th International Symposium on Nondestructive testing of wood. University of California, California

Apiolaza LA (2009) Very early selection for solid wood quality: screening for early winners. Ann For Sci 66:601-607

Apiolaza LA, Butterfield B, Chauhan SS, Walker JCF (2011) Characterization of mechanically perturbed young stems: Can it be used for wood quality screening? Ann For Sci 68:407-414

Booker RE, Sell J (1998) The nanostructure of the cell wall of softwoods and its functions in a living tree. Holz Roh Werkst 56:1-8

Burdon RD (1975) Compression wood in Pinus radiata clones on four different sites. NZ J For Sci 5:152-164

Donaldson LA, Grace J, Downes GM (2004) Within tree variation in anatomical properties of compression wood in radiata pine. IAWA J 25:253-271

Evans R (2000) Measuring wood and fibre properties. In: WTRC Workshop 2000. Wood Technology Research Centre, University of Canterbury, New Zealand. pp 15-20

Floyd S (2005) Effect of hemicelluloses on longitudinal shrinkage in wood. In: Entwistle KM, Walker JCF (eds) The Hemicellulose Workshop 2005. Wood Technology Research Centre, University of Canterbury, New Zealand, pp 115-120

Hai PH, Jansson G, Hannrup B, Harwood C, Thinh HH (2009) Use of wood shrinkage characteristics in breeding of fast-grown Acacia auriculiformis A. Cunn. ex Benth in Vietnam. Ann For Sci 66:611

Halabe UB, Bidigalu GM, GangaRao HVS, Ross R (1997) Nondestructive evaluation of green wood using stress wave and transverse vibration techniques. Mater Eval 55:1013-1018

Horvath B, Peszlen I, Peralta P, Horvath L, Kasal B, Li L (2010) Elastic modulus determination of transgenic aspen using a dynamic mechanical analyzer in static bending mode. For Prod J 60:296-300

Huang CL, Lambeth C (2007) Stress wave velocity of loblolly pine seedlings. In: Walker JCF (ed) The compromised wood workshop. Christchurch, New Zealand, pp 37-50

Huang CL, Lindström H, Nakada R, Ralston J (2003) Cell wall structure and wood properties determined by acoustics-a selective review. Holz Roh Werkst 61:321-335

Kollman F, Côté WA (1968) Principles of Wood Science and Technology 1. Solid Wood. Springer, Berlin

Kretschmann DE, Cramer SM (2007) The role of earlywood and latewood properties on dimensional stability of loblolly pine. In: Walker JCF (ed) The compromised wood workshop, Christchurch, New Zealand, 215-236

Lachenbruch B, Droppelmann F, Balocchi C, Peredo M, Perez E (2010) Stem form and compression wood formation in young Pinus radiata trees. Can J For Res 40:26-36

Li L, Wu HX (2005) Efficiency of early selection for rotation-aged growth and wood density traits in Pinus radiata. Can J For Res 35:2019-2029

Lindström H, Harris P, Nakada R (2002) Methods for measuring stiffness of young trees. Holz Roh Werkst 60:165-174

Lindström H, Evans R, Harris P, Sorensson C (2004) Stiffness and wood variation of 3 -year old Pinus radiata clones. Wood Sci Technol 38:579-597

Nakada R (2007) Within-tree variation of wood characteristics in conifers and the anatomical characteristics specific to very young trees. In: Walker JCF (ed) The compromised wood workshop, Christchurch, New Zealand, 51-67

Ross R, Pellerin R (1991) NDE of green material with stress waves: Preliminary results using dimension lumber. For Prod J 41:57-59

Sierra de Grado R, Pando V, Martínez SP, Peñalvo A, Báscones E, Moulia B (2008) Biomechanical differences in the stem 
straightening process among Pinus pinaster provenances: A new approach for early selection of stem straightness. Tree Physiol $28: 835-846$

Timell TE (1986) Compression wood in gymnosperms, vol 1. Springer Verlag, Heidelberg, 706

Wang X, Ross RJ, McClellan M, Barbour RJ, Erickson JR, Forsman JW, McGinnis GD (2000) Strength and stiffness assessment of standing trees using a nondestructive stress wave technique. Research Paper Forest Products Laboratory, USDA Forest Service (FPL-RP-585), 9 pp
Wu HX, Mike BP, Yang JL, Ivković M, Tony AM (2007) Efficiency of early selection for rotation-aged wood quality traits in radiata pine. Ann For Sci 64:1-9

Yamashita S, Yoshida M, Takayama S, Okuyama T (2007) Stemrighting mechanism in gymnosperm trees deduced from limitations in compression wood development. Ann Bot 99:487-493

Yoshida M, Okuda T, Okuyama T (2000) Tension wood and growth stress induced by artificial inclination in Liriodendron tulipifera Linn. and Prunus spachiana Kitamura f. ascendens Kitamura. Ann For Sci 57:739-746 